EESTI NSV TEADUSTE AKADEEMIA TOIMETISED. 28, KOIDE

KEEMIA. 1979, NR. 4

ИЗВЕСТИЯ АКАДЕМИИ НАУК ЭСТОНСКОП ССР. ТОМ 28

Химия. 1979, № 4

удК 553.96.002.61

H. СТАРОСТИНА, К. УРОВ

\title{
К ХАРАКТЕРИСТИКЕ ОРГАНИЧЕСКОЙ МАССЫ КАНСКО-АЧИНСКОГО БУРОГО УГЛЯ
}

\author{
Представлена О. Эйзеном
}

Канско-Ачинский буроугольный бассейн является одним из крупнейших в мире. Добыча угля здесь возможна эффективным открытым способом, поэтому вопросы промышленного использования этого горючего ископаемого привлекли широкое внимание ученых (см., например, $\left.\left[{ }^{1-3}\right]\right)$. Меньше исследований посвящено химическому составу органической массы указанного каустобиолита [4-10]. В настоящей работе представлены результаты изучения органического вещества (OB) канско-ачинского угля по схеме, разработанной в Институте химии АН Эстонской ССР [11] и базирующейся в основном на хроматографических методах анализа.

Канско-ачинский бурый уголь образовался в юрский период в континентальном пресноводном бассейне ['], при этом исходный органический и минеральный материал был частично занесен в застойный водоем водными потоками $\left[{ }^{12}\right]$. Этот уголь типично гумусовый, и в его петрографическом составе превалирует витринит $\left[{ }^{13}\right]$.

Исходный образец угля $\left(\mathrm{Б}_{2}\right)$ был отобран на Ирша-Бородинском разрезе из Бородинского пласта на месте пикетов 9 и 10 (третий горизонт обновленного забоя, глубина $8 m$ ).

Характеристика исходного угля (вес. \%): Wa 10,6 ; Ac $^{\text {9 }}, 0$; условная органическая масса 90,0. Содержание спиртобензольного битумоида на сухой уголь (рядом в скобках - на органическую массу), вес. \%: 2,5 $(2,8)$; выход продуктов полукоксования из дебитуминированного угля: смола $6,0(6,7)$; вода разложения $10,4(11,6)$; полукокс $67,7(64,4)$; газ и потери $15,9(17,7)$. Очевидно, при полукоксовании неэкстрагированного угля значительная часть смолы образуется за счет богатого водородом битумоида, на что указывалось и ранее [14], и поэтому состав битумоида в известной мере определяет состав смолы.

Образующийся при термическом разложении угля газ содержит (об. \% ): $\mathrm{CO}_{2} 60,1 ; \mathrm{CH}_{4}$ 19,4; $\mathrm{CO} 8,0 ; \mathrm{H}_{2} 4,3 ; \mathrm{C}_{2} \mathrm{H}_{6} 3,2 ; \mathrm{C}_{2} \mathrm{H}_{4} 2,9 ; \mathrm{C}_{3} \mathrm{H}_{6} 0,9$;

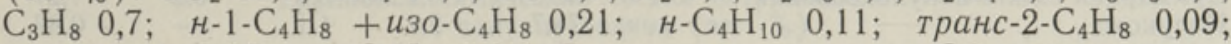
цис-2- $\mathrm{C}_{4} \mathrm{H}_{8}$ 0,06; изо- $\mathrm{C}_{4} \mathrm{H}_{10}$ 0,03. Высокое содержание $\mathrm{CO}_{2}$ типично для газа полукоксования бурого угля.

Смола полукоксования (плотность 1,0125$)$ характеризуется низким атомарным отношением $\mathrm{H} / \mathrm{C}$ и значительным содержанием гетероатомов (табл. 1) и гетероатомных соединений (табл. 2). Необычно, что в смоле полукоксования содержится больше гетероатомов, чем в битумоиде. Однако гетероатомные соединения составляют все же более $80 \%$ битумоида, что указывает на его сингенетический характер $\left[{ }^{15}\right]$.

Интересно, что по инфракрасному спектру (рис. 1), если сравнить его с типогыми спектрами различных генетических групп битумоидов $\left[{ }^{16}\right]$,

1 ENSV TA Toimetised. K -41979 


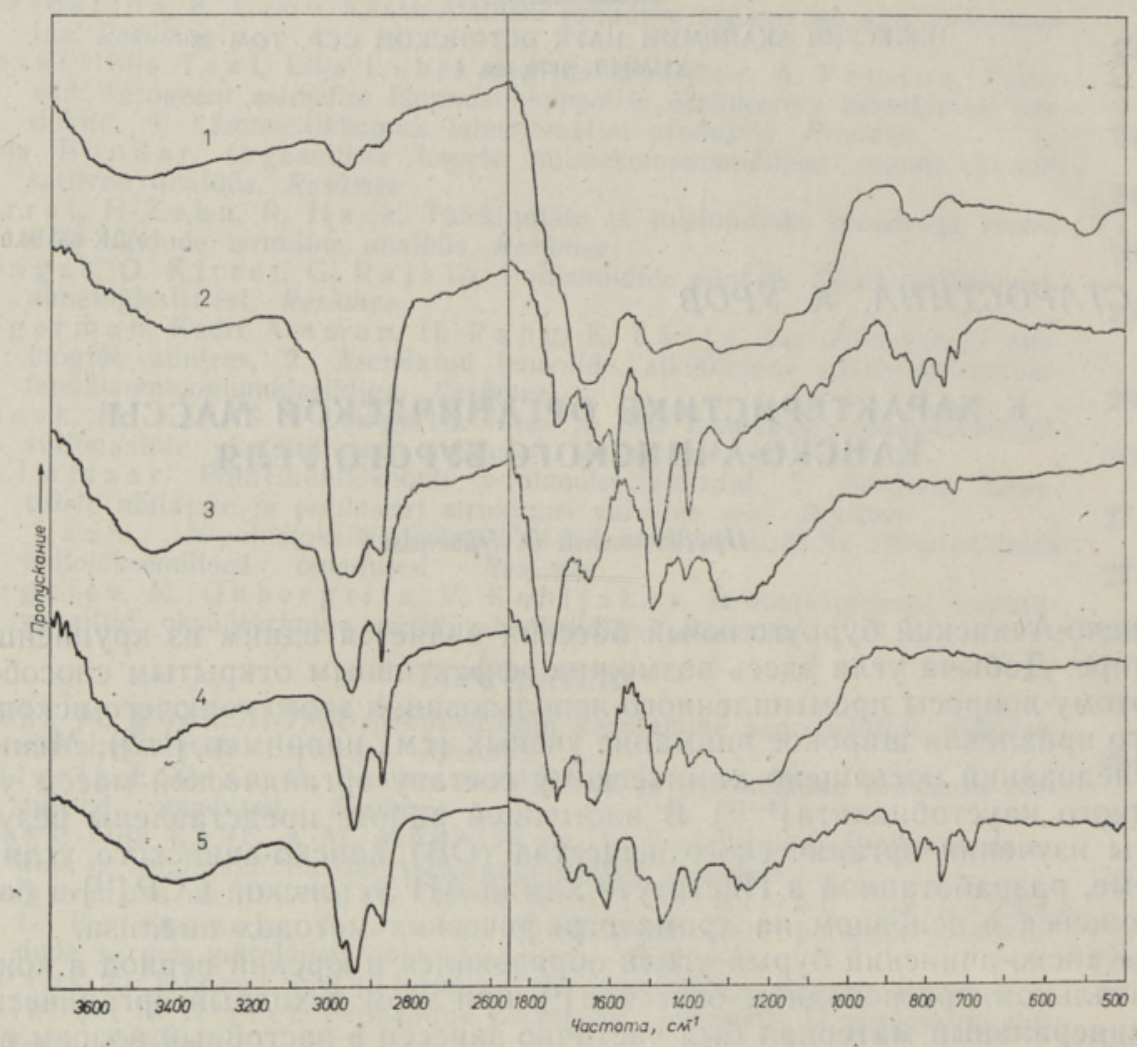

Рис. 1. Инфракрасные спектры: исходдного угля $(1)$, его суммарного битумоида (2), эфирорастворимых (3) и нерастворимых в. эфире (4) кислот битумоида, суммарной смолы полукоксования (5).

Таблица 1

Результаты элементного анализа (вес. \%)

\begin{tabular}{l|c|c|c|c|c}
\hline \multicolumn{1}{c|}{ Анализировавшийся продукт } & C & H & N & $\begin{array}{c}\text { O+S } \\
\text { (по раз- } \\
\text { ности) }\end{array}$ & $\begin{array}{c}\text { H/C } \\
\text { атом. }\end{array}$ \\
\hline Oрганическая масса исходного угля & 76,7 & 3,9 & 1,1 & $18,3 *$ & 0,61 \\
Суммарный битумонд & 84,5 & 10,1 & - & 5,4 & 1,43 \\
Эфирорастворимые кислоты битумонда & 76,7 & 9,0 & - & 14,3 & 1,41 \\
Нерастворимые в эфире кислоты биту- & 64,8 & 6,6 & 0,7 & 27,9 & 1,22 \\
$\quad$ монда & 82,3 & 8,7 & 0,8 & $8,2^{* *}$ & 1,27 \\
Суммарная смола полукоксования & 71,7 & 2,2 & 1,1 & - & 0,37 \\
Полукокс & & & & & \\
* Сера 0,3\%. & & & & &
\end{tabular}

растворимая часть органической массы канско-ачинского угля приближается к вторичным битумоидам. Видимо, типизация битумоидов по спектрам, разработанная для рассеянного, преимущественно сапропелевого OB, требует уточнения для случая концентрированных гумолитов.

н-Алканы битумоида исследовавшегося угля (рис. 2) отличаются от соответствующей группы соединений александрийского $\left[{ }^{17}\right]$ и ново-дмит- 


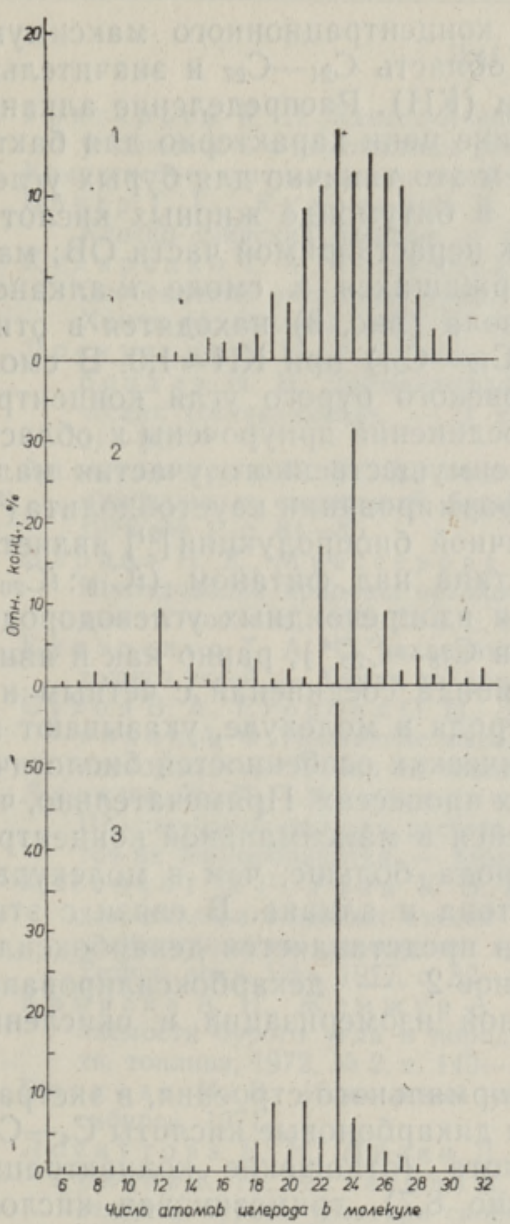

Рис. 2. Распределение по длине непи: $九$-алканов (1), предельных жирных кислот нормального строения (2) и метил-н-алкилкетонов (3) битумонда канско-ачинского угля.

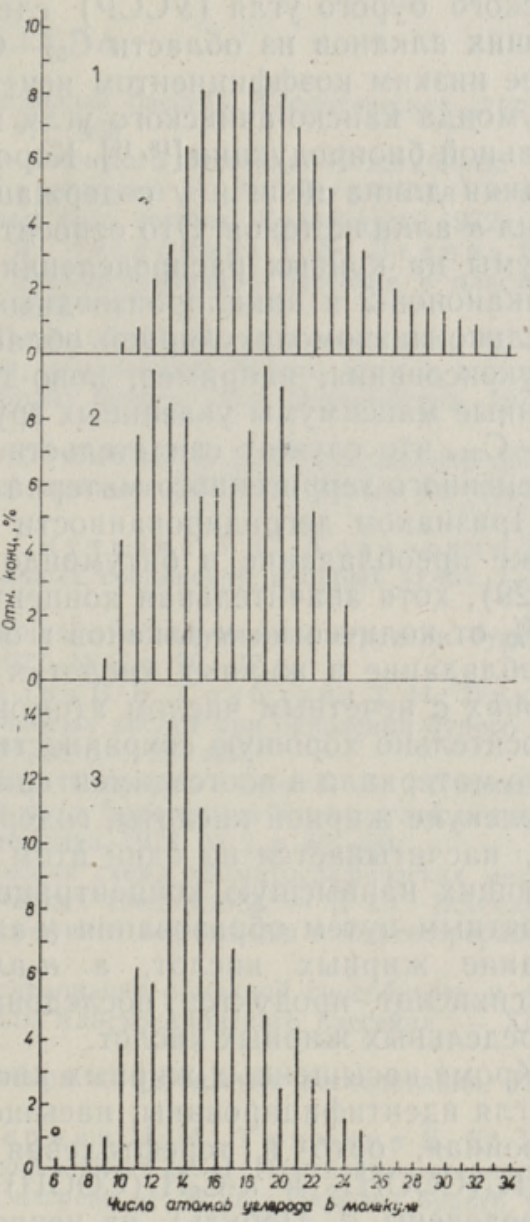

Рис. 3. Распределение по числу атомов углерода в молекуле: $\boldsymbol{H}$-алканов (1), алкилпроизводных бензола (2) и метил-н-алкилкетонов (3) смолы полукоксования канско-ачинского угля.

Групповой химический состав битумоида и смолы полукоксования (вес. \%)

\begin{tabular}{l|l|l}
\hline Групповой компонент & $\begin{array}{l}\text { Биту- } \\
\text { моид }\end{array}$ & $\begin{array}{c}\text { Смола } \\
\text { полукок- } \\
\text { сования }\end{array}$ \\
\hline
\end{tabular}

Неароматические углеводороды

Одноядерные ароматические углеводороды

Конденсированные ароматические углеводороды

Нейтральные гетероатомные соединения

Кислотные соединения

из них нерастворимые в эфире
12,2

6,5

30,4

25,4

25,5 
ровского бурого угля (УССР) сдвигом концентрационного максимума высших алканов из области $\mathrm{C}_{27}-\mathrm{C}_{31}$ в область $\mathrm{C}_{21}-\mathrm{C}_{27}$ и значительно более низким коэффициентом нечетности (KН). Распределение алканов битумоида канско-ачинского угля по длине цепи характерно для бактериальной биопродукции $\left[{ }^{18,19}\right]$. Короче, чем это типично для бурых углей, средняя длина цепи и у содержащихся в битумоиде жирных кислот и метил-н-алкилкетонов. Это относится и к нерастворимой части OB: максимумы на кривых распределения содержащихся в смоле $H$-алканов, $\boldsymbol{H}$-алканонов-2 и алкилпроизводных бензола (рис. 3 ) находятся в относительно низкомолекулярной области $\left(\mathrm{C}_{12}-\mathrm{C}_{21}\right)$ при $\mathrm{KH} \approx 1,0$. В смоле полукоксования, например, ново-дмитровского бурого угля концентрационные максимумы указанных групп соединений приурочены к области $\mathrm{C}_{25}-\mathrm{C}_{31}$, что служит свидетельством преимущественного участия малоизмененного терригенного материала в формировании каустобиолита $\left[{ }^{20}\right]$.

Признаком деградированности первичной биопродукции $\left[{ }^{21}\right]$ является также преобладание в битумоиде пристана над фитаном $\left(i \mathrm{C}_{19}: i \mathrm{C}_{20}=\right.$ $=1,29)$, хотя значительная концентрация изопреноидных углеводородов $\left(61 \%\right.$ от количества $\boldsymbol{H}$-алканов в области $\left.\mathrm{C}_{18}-\mathrm{C}_{20}{ }^{*}\right)$, равно как и явное преобладание в жирных кислотах битумоида соединений с четным и в кетонах с нечетным числом атомов углерода в молекуле, указывают на относительно хорошую сохранность химических особенностей биологического материала в постседиментационных процессах. Примечательно, что в молекуле жирной кислоты, содержащейся в максимальной концентрации, насчитывается на один атом углерода больше, чем в молекулах, имеющих наивысшую концентрацию кетона и алкана. В связи с этим вероятным путем образования $\boldsymbol{H}$-алканов представляется декарбоксилирование жирных кислот, а $H$-алканонов-2 - декарбоксилирование $\beta$-оксикислот, продуктов последовательной изомеризации и окисления непредельных жирных кислот.

Кроме насыщенных жирных кислот нормального строения, в экстракте угля идентифицированы: насыщенные дикарбоновые кислоты $\mathrm{C}_{4}-\mathrm{C}_{11}$, бензойная, орто- и терефталевая кислота (отношение концентраций $o-\mathrm{C}_{6} \mathrm{H}_{4}(\mathrm{COOH})_{2}$ и $n-\mathrm{C}_{6} \mathrm{H}_{4}(\mathrm{COOH})_{2}$ равно 8,7), тримезиновая. кислота (определены Л. Побуль), из непредельных - олеиновая кислота.

Кислотные соединения смолы полукоксования представлены фенолами, преимущественно одноатомными. Судя по составу кетонов смолы (рис. 3), карбонилсодержащие участки в нерастворимой части ОВ отличаются от имеющихся в битумоиде: они значительно короче их $\left(\mathrm{C}_{13}-\mathrm{C}_{17}\right)$, и КН близок к 1,0 . В отношении распределения по величине молекул $\boldsymbol{H}$-алканоны-2 смолы соотносимы с.более легкой частыю алкилпроизводных бензола, что допускает образование последних через промежуточную ступень $\beta$-кетокислот $\left[{ }^{22}\right]$. Алкилпроизводные бензола $\mathrm{C}_{18}-\mathrm{C}_{24}$ но распределению числа атомов углерода в молекуле примыкают к $H$-алканам; циклизация углеродных цепей имеет место как в ходе термической деструкции, так и при естественном преобразовании захороненного ОВ.

Таким образом, наряду с представляющими практический интерес сведениями о химическом составе смолы полукоксования канско-ачинского угля, получены данные о своеобразии этого каустобиолита в генетическом отношении: общий для всех бурых углей терригенный материал здесь трансформирован глубже, чем в ряде других бурых углей, что, возможно, связано с аллохтонным характером органической массы канско-ачинского угля $\left[{ }^{12}\right]$.

* В битумоиде обнаружено также значительное количество циклических изопреноидов и, предположнтельно, их кислородсодержащих аналогов. 


\section{Л И ТЕРАТ У РА}

1. Григорьев К. Н. Канско-Ачинский угольный бассейн. Геологическое строение, угленосность и перспективы развития. М., 1968.

2. Комплексное использование углей Қанско-Ачинского бассейна. Новосибнрск, 1971.

3. Бруер Г. Г., Кудряв ці в В. С., Л арионов М. Н., Турубинин М. Г. Канско-Ачинский бассейн - топливная база страны. Красноярск, 1972.

4. Кухаренко Т. А., Толчинская Р. Я., Чеснокова Т. В., Левина И. В. Особенности окисления бурых углей Канско-Ачннского бассейна в пласте. Химия тв. топлива, 1967, № 2, с. 20-30.

5. Лоскутов а Е. Н., М атвеев В. Е., Ге р ман Н. M., Ширяева К. Н., Любе ц к я Н. Н. Дериватографическое исследование бурого угля и его химических составляющих. - В кн.: Пиролиз бурого угля. Новосибирск, 1973, с. $21-34$

6. Александров И. В., Орлов В. В., К амнев а А. И. Исследование органоминеральных соединений бурых углей методом ЭПР. - Химия. тв. топлива, 1976, № 1, c. $81-85$.

7. Л арина Н. К., Миессерова О. К., Смуткина 3. С., Коваленко Г. С. Исследование природы органоминеральных соединений в бурых углях. - Химия тв. топлива, 1976 , № 3, с. $44-50$.

8. Кух а ренко Т. А. О механизме окисления и молекулярном строении бурого и тощего углей. - Химия тв. топлива, 1977, № 3, с. $70-77$.

9. Сухов В.А., Егорова О.И., З а мыслов В.Б., Соколова Т. Н., Луковн и ко в А. Ф. Измененне выхода гуминовых кислот при окислении бурого угля кислородом. - Химия тв. топлива, 1977, № 6, с. 38-43.

10. Л арина Н. К., Миессерова О. К., Скрипченко Г. Б. Применение ИК-спектроскопии для расчета структурных параметров бурых углей и продуктов их термообработки. - Химия тв. топлива, 1978 , № 2, с. $42-50$.

11. Клесм ен т И. Р., У ров К. Э. Комплексная схема хроматографических методов для анализа сложных смесей органических соединений. - В кн.: Всесоюзная конференция по применению хроматографии в нефтехимии и нефтепереработке. Тезисы докл. Уфа, 1977, с. $82-83$.

12. К а мн в а А. И., Ж ем ж у А. И. Исследование обменной способности и окисляемости бурого угля и породы кровли Канско-Ачинского бассейна. - Химия тв. топлива, 1972 , № 2 , с. $140-142$.

13. Волкова И. В. Ископаемые угли Сибири и методы их исследования. Новосибирск, 1971.

14. Лоскутова Е. Н., Лисин Д. М., Герман Н. М., Тюнюков Б. К., Ши р я е в а К. Н., М а т с о в а К. А., Л юбец ка я Н. Н. Изменение органических веществ бурого угля при скоростном нагреве. - В кн.: Пиролиз бурого угля. Новосибирск, 1973, с. 117-127.

15. Н е р уч е в С. Г. Нефтепроизводящие свиты и миграция нефти. Л., 1962.

16. Н е р у ч е в С. Г. Нефтепроизводящие свиты и миграция нефти. Л., 1969.

17. Гу ляева Н. Д., Арефьев О. А., Е мец Т. Т., Соколов В. Л., Петров А. А. Закономерности распределения нормальных и изопреноидных алканов в гумусовых углях. - Химия тв. топлива, 1978, № 1, с. 45-51.

18. Jones, J. G. Studies on lipids of soil micro-organisms with particular reference to hydrocarbons. - J. Gen. Microbiol., 1969, v. 59, N 2, p. $145-152$.

19. Johnson, R. W., Calder, J. A. Early diagenesis of fatty acids and hydrocarbons in a salt marsh environment. - Geochim. Cosmochim. Acta, 1973, v. $37, \mathrm{~N} 8$, p. $1943-1955$.

20. Thompson, S., Eglinton, G. The fractionation of a recent sediment for organic geochemical analysis. - Geochim. Cosmochim. Acta, 1978, v. 42, N 2, p. $199-207$.

21. Шля хо в А. Ф., В олко в а Л. Г. Стереохимия изопреноидных алканов и возможные пути их образования в осадочных породах. - Геохимия, 1977, № 9, с. $1418-1423$

22. Клесмент И. Р., Риккен Ю. Т., У ров К. Э. Характеристика оленекского богхеда по данным термической деструкции. - Химия тв. топлива, 1977, № 2, c. $126-132$.

\section{Ннститут химии}

Академии наук Эстонской ССР

Энергетический научно-исследовательский институт им. Г. М. Кржсижановского
Поступила в редакцию 16/XII 1978 
N. STAROSTINA, K. UROV

\section{KANSK-ATŠINSKI PRUUNSOE ORGAANILISE AINE ISELOOMUSTUS}

On esitatud Kansk-Atšinski basseini pruunsöe lahustuva osa ja debitumineeritud söe termilise lagunemise produktide keemilise koostise kromatograafilise uurimise tulemused. Tehti kindlaks $n$-alkaanide, $n$-alkanoonide-2, küllastunud rasvhapete ja benseeni alküülderivaatide jaotus vastavalt süsinikuaatomite arvule molekulis. Võrreldes rea teiste pruunsütega on Kansk-Atšinski söe bioloogiline lähteaine rohkem muundunud.

N. STAROSTINA, K. UROV

\section{ON THE CHARACTERIZATION OF THE ORGANIC MATTER OF KANSK-ACHINSK BROWN COAL}

The chemical composition of bitumen and of thermal degradation products of the Kansk-Achinsk brown coal has been investigated using chromatographic methods. The distribution of $n$-alkanes, $n$-alkanones-2, saturated $n$-fatty acids and alkyl derivatives of benzene according to the number of carbon atoms in the molecule has been established. In comparison with several other brown coals, the biological source material of the Kansk-Achinsk coal during its formation has changed more profoundly. 